\title{
Trends in the Risk of Mortality due to Cardiovascular Diseases in Five Brazilian Geographic Regions from 1979 to 1996
}

\author{
Maria de Fátima Marinho de Souza, Ari Timerman, Carlos Vicente Serrano Jr, Raul D. Santos, \\ Antonio de Pádua Mansur \\ São Paulo, SP - Brazil
}

Objective - To analyze the trends in risk of death due to cardiovascular diseases in the northern, northeastern, southern, southeastern, and central western Brazilian geographic regions from 1979 to 1996.

Methods - Data on mortality due to cardiovascular, cardiac ischemic, and cerebrovascular diseases in 5 Brazilian geographic regions were obtained from the Ministry of Health. Population estimates for the time period from 1978 to 1996 in the 5 Brazilian geographic regions were calculated by interpolation with the Lagrange method, based on the census data from 1970, 1980, 1991, and the population count of 1996, for each age bracket and sex. Trends were analyzed with the multiple linear regression model.

Results - Cardiovascular diseases showed a declining trend in the southern, southeastern, and northern Brazilian geographic regions in all age brackets and for both sexes. In the northeastern and central western regions, an increasing trend in the risk of death due to cardiovascular diseases occurred, except for the age bracket from 30 to 39 years, which showed a slight reduction. This resulted from the trends of cardiac ischemic and cerebrovascular diseases. The analysis of the trend in the northeastern and northern regions was impaired by the great proportion of poorly defined causes of death.

Conclusion - The risk of death due to cardiovascular, cerebrovascular, and cardiac ischemic diseases decreased in the southern and southeastern regions, which are the most developed regions in the country, and increased in the least developed regions, mainly in the central western region.

Key words: epidemiology, cardiovascular diseases, cardiac ischemic diseases, cerebrovascular diseases, atherosclerosis

Departamento de Medicina Preventiva da Faculdade de Medicina, Instituto do Coração do Hospital das Clínicas - FMUSP, SBC/FUNCOR and Departamento de Aterosclerose da SBC

Mailing address: Ari Timerman - SBC/FUNCOR - Rua Beira Rio 45 - 3o - 04548-050 São Paulo, SP, Brazil

English version by Stela Maris C. e Gandour
Cardiovascular diseases are the major cause of death in developed countries ${ }^{1-2}$. In Latin America, cardiovascular diseases account for $1 / 3$ of all deaths ${ }^{3}$. They are also the major cause of death in Brazil ${ }^{4}$. When the total number of deaths was considered, cardiovascular diseases accounted for $11.8 \%, 30.8 \%$, and $28 \%$, respectively, in the years 1930 , 1980, and 1994. In 1994, the proportional mortality was $34 \%$ for individuals over the age of 30 years. The trend in mortality due to cardiovascular, cardiac ischemic, and cerebrovascular diseases has been declining in developed countries since the 1960s. The analysis performed by Uemura and Pisa $^{5}$ showed a significant reduction in cardiovascular diseases in countries like Japan (-36.4\% for males and $-41.3 \%$ for females) and Australia (-32.1\% for males and $-39.2 \%$ for females), and a significant increase in most eastern European countries (for example: $34.1 \%$ in Bulgaria and $31.3 \%$ in Poland). The same declining trend in mortality due to cardiac ischemic and cerebrovascular diseases has been observed in the municipality and state of São Paulo since $1976^{6-9}$. The decline in the risk of death due to cerebrovascular diseases in the municipality of São Paulo in the period from 1975 to 1981 was $13.6 \%$ for males and $8.5 \%$ for females ${ }^{9}$. In Brazil, a slight increase in the risk of death due to cardiovascular diseases occurred from 1979 to 1984 , and, after that, a progressive declining trend was observed until $1996^{4}$. Most authors believe that the decline in mortality due to cardiovascular diseases in developed countries is mainly due to the control of risk factors ${ }^{10,11}$. Improvement in diagnosis and medical interventions has also helped patient survival ${ }^{12}$. Other studies show that the treatment and control of arterial hypertension have contributed to the decline in cerebrovascular diseases ${ }^{13,14}$. The objective of this study was to analyze the trend in mortality from cardiovascular, cardiac ischemic, and cerebrovascular diseases in 5 Brazilian geographic regions according to sex and age bracket from 1979 to 1996.

\section{Methods}

Data on mortality due to cardiovascular, cardiac ische- 
mic, and cerebrovascular diseases in the 5 Brazilian geographic regions were obtained via the Ministry of Health for the period from 1979 to $1996^{15}$. The population estimates on the $1^{\text {st }}$ of July of the years from 1978 to 1996 in the 5 Brazilian geographic regions were calculated using interpolation with the Lagrange method ${ }^{16}$ based on census data from 1970, 1980, 1991, and the population count of 1996 for each age bracket and sex ${ }^{17-20}$.

The multiple linear regression model was used ${ }^{21}$. Information on mortality due to all cardiovascular diseases was modeled, followed by data on mortality due to cardiac ischemic and cerebrovascular diseases. The natural logarithm of the raw coefficient (number of deaths/population estimated on the $1^{\text {st }}$ of July) was used as a dependent variable. The cardiac ischemic and cerebrovascular diseases, the Brazilian geographic regions (Central Western, Northeast, North, Southeast, and South), sex, years in the calendar of the study, age bracket (30-39, 40-49, 50-59, 60-69, and above 70 ), and their respective interactions were the independent variables. The partial $\mathrm{F}$ test was performed to extract the nonsignificant interactions for the models. The objective was to reach the end of the modeling process with the lowest number of possible interactions. Adjustment of the models was tested by the analysis of the residues and the correlation coefficients. Analysis of the residues was performed using graphs of the envelope type and graphs of the model residues versus adjusted values to assess the adjustment of the models adopted.

\section{Results}

The trends observed are shown as figures (figs. 1 to 6), where the coefficients are presented in natural logarithms, according to age bracket and sex, and also in 2 tables with raw coefficients for the years 1979, 1987, and 1996 of the series and the percentage variation between the years 1979 and 1996. The analysis of residues showed a good adjustment of the multiple linear regression model. A total of $3,764,265$ deaths due to cardiovascular diseases, 1,113,281 deaths due to cardiac ischemic diseases, and 1,289,952 deaths due to cerebrovascular diseases was observed in the period from 1979 to 1996.

The coefficients and percentage variations of mortality due to cardiovascular diseases are shown in table I. A declining trend in the incidence of cardiovascular diseases was observed in the southeastern, southern, and northern regions for all age brackets and both sexes in the period from 1979 to 1996. In the northeastern and central western regions, an increasing trend in the risk of death was observed for all age brackets analyzed, except for the 30-to-39-year interval. A reduction in the risk of death for the female sex in the age bracket from 40 to 49 years and above 70 years of age was observed in the central western region. At the beginning of the series in 1979, the risk of death due to cardiovascular diseases was higher in the southeastern and southern regions for all age brackets and both sexes. At the end of the series in 1996, this risk in the central western region exceeded that in the southern region in the age bracket

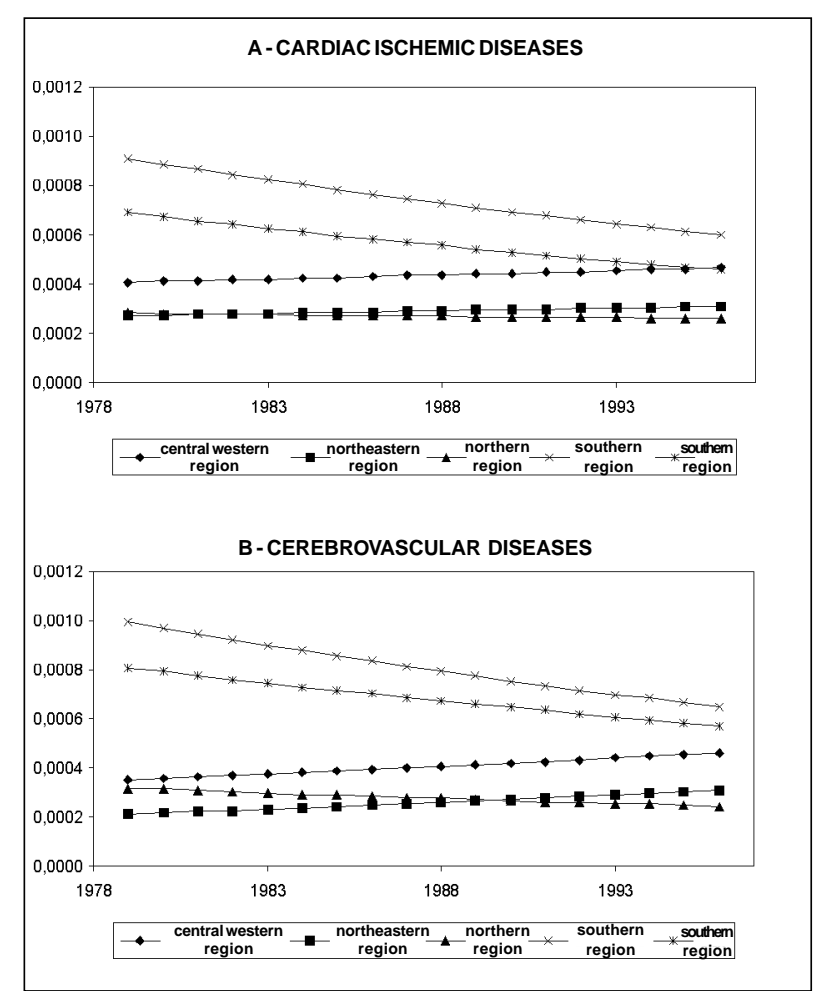

Figure 1-Model adjusted to the Brazilian geographic regions for the 40-to-49-year age bracket and the male sex, according to disease.

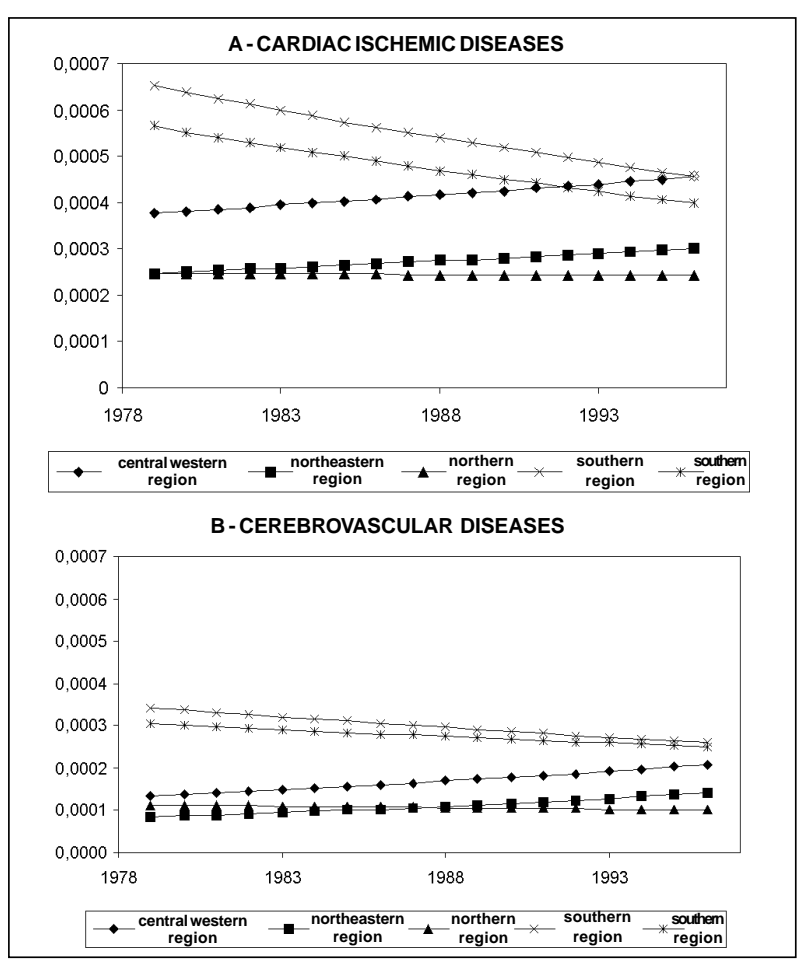

Figure 2 - Model adjusted to the Brazilian geographic regions for the 40-to-49-year age bracket and the female sex, according to disease.

from 30 to 49 years and for both sexes. In the northeastern region, a lower risk than that in the other regions was observed. However, this risk proved to be crescent, increasing 5\% 


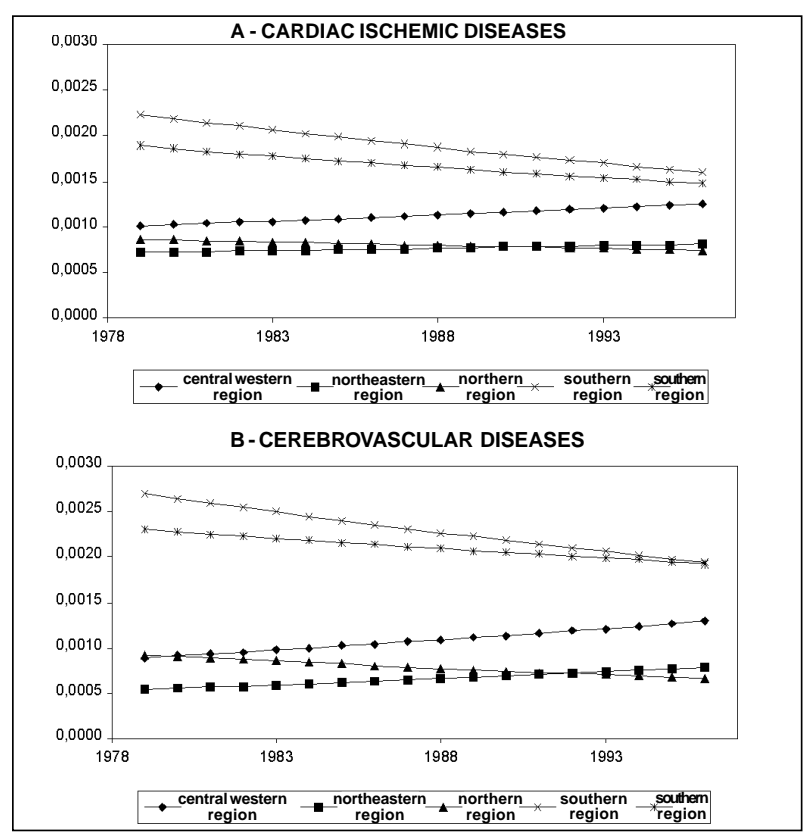

Figure 3 - Model adjusted to the Brazilian geographic regions for the 50-to-59-year age bracket and the male sex, according to disease

among females in the age bracket from 40 to 49 years, and $11 \%$ in the age bracket from 50 to 59 years. Among males, the risk increased $7 \%$ in the age bracket from 40 to 49 years and $12 \%$ in the age bracket from 50 to 59 years. In general, the northern region had the $2^{\text {nd }}$ lowest risk of death, and the drop in mortality was higher among males than among females for the age bracket from 40 to 60 years.

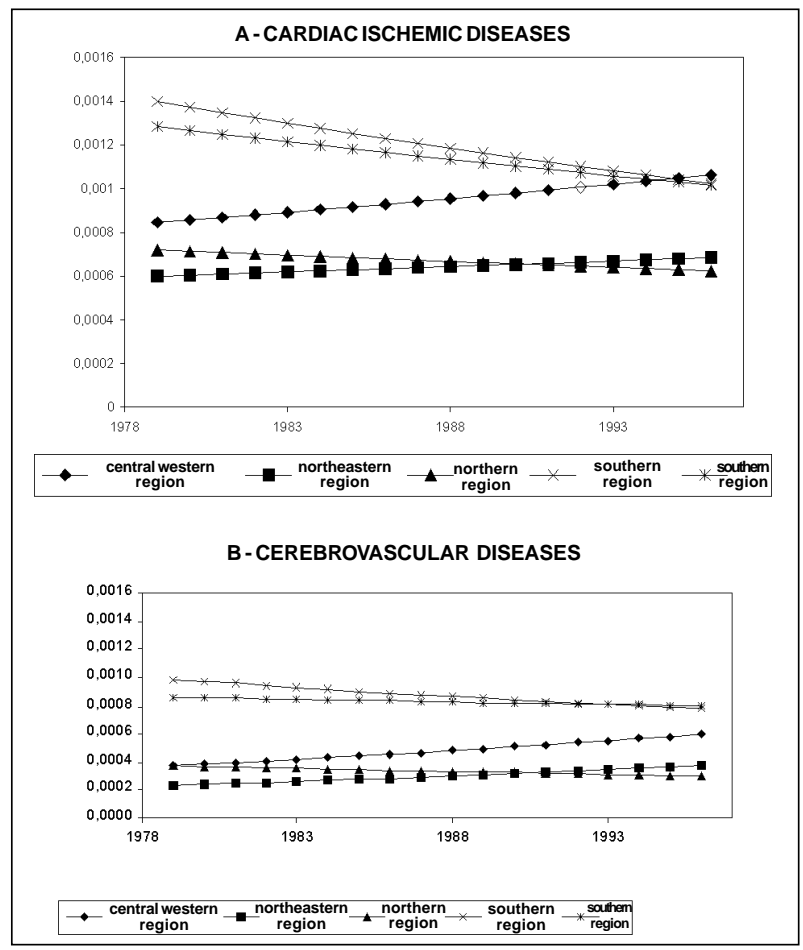

Figure 4 - Model adjusted to the Brazilian geographic regions for the 50-to-59-year age bracket and the female sex, according to disease.

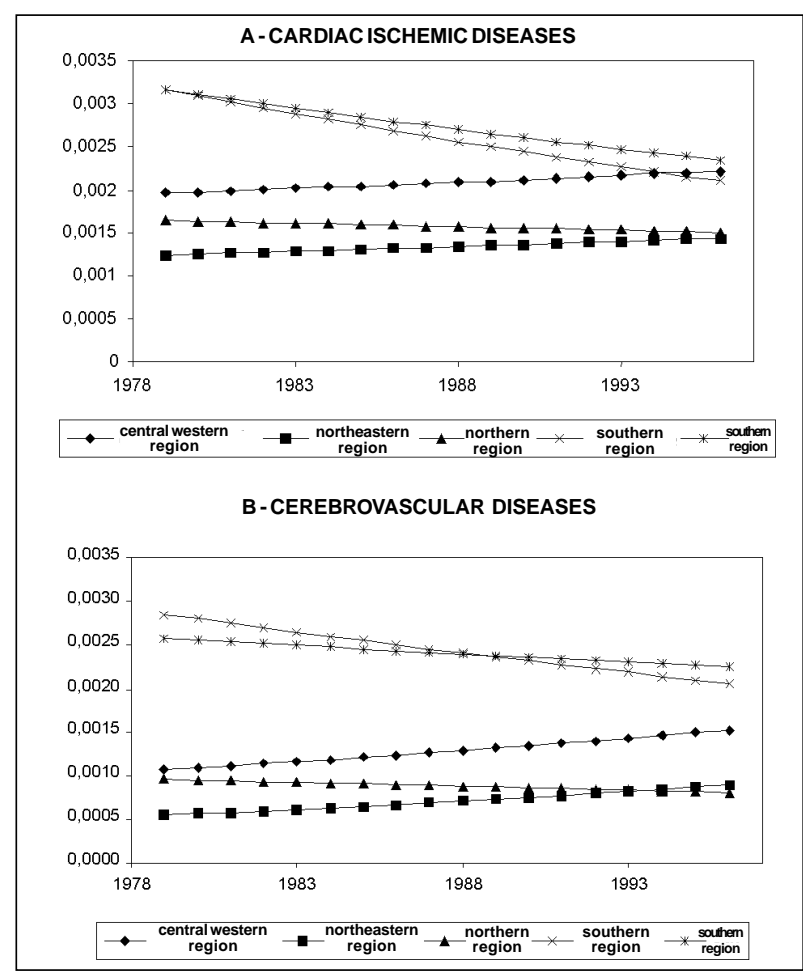

Figure 5 - Model adjusted to the Brazilian geographic regions for the 60-to-69-year age bracket and the female sex, according to disease.

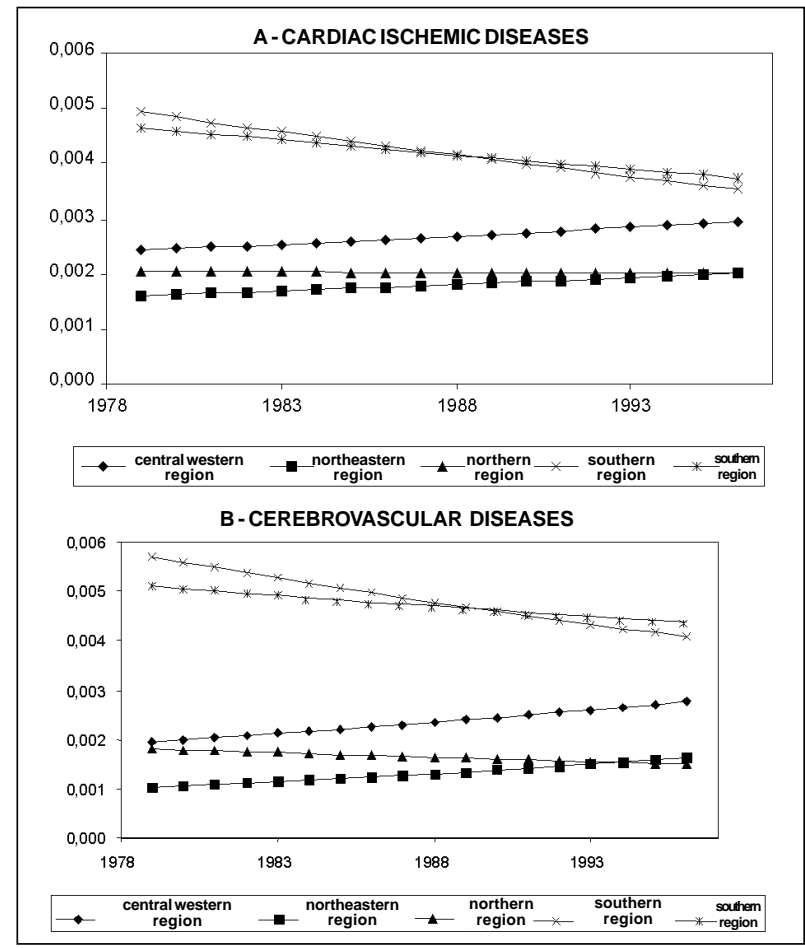

Figure 6 - Model adjusted to the Brazilian geographic regions for the 60-to-69-year age bracket and the male sex, according to disease.

The coefficients and percentage variations of mortality due to cardiac ischemic diseases are shown in table II. Cardiac ischemic diseases exhibited a declining trend in the southern, southeastern, and northern regions for all age 




brackets and for both sexes in the period from 1979 to 1996. In the central western and northeastern regions, an increase in cardiac ischemic diseases was observed for males and females during this period. The risk of death in the central western region was higher than that in the northeastern region; since the beginning of the observation period, however, the percentage variation in the risk of death has always been higher in the northeastern region than in the central western region. The highest risk of death was observed in the southeastern region for all age brackets and both sexes in the period studied. The southern region had the $2^{\text {nd }}$ highest risk of death, except for the year 1996 in the age bracket above 60 years. Both regions exhibited a declining trend in the risk of death, which was more marked in the southeastern region (figs. $1 \mathrm{~A}$ to $6 \mathrm{~A}$ ).

The coefficients and percentage variations in mortality due to cerebrovascular diseases are shown in table II. Cerebrovascular diseases showed a declining trend in the southern, southeastern, and northern regions for all age brackets and both sexes in the period from 1979 to 1996. In the central western and northeastern regions, an increase in cerebrovascular diseases was observed in the period studied for both sexes, except in the central western region in the age bracket from 30 to 39 years for both sexes and above 70 years for females, and in the northeastern region for females from 30 to 39 years and $\geq 70$ years. The risk of death in the central western region was higher than that in the northeastern region, but the percentage variation of the risk of death showed great differences in the age bracket and sex. In the age bracket from 40 to 69 years, an increasing trend in the risk of death occurred, and it was similar for both sexes in the age bracket from 40 to 69 years, and higher for males in the age range from 50 to 59 years. The highest risk of death was observed in the southeastern region for all age brackets and both sexes in the period studied, except in the age bracket $\geq 70$ years. The southern region had the $2^{\text {nd }}$ highest risk of death, except in the year of 1996 for the age bracket above 60 years, and in all the other years for the age bracket $\geq 70$ years. In general, both regions showed a declining trend in the risk of death, which was more marked in the southeastern region (figs. 1B to 6B).

\section{Discussion}

This study showed different trends in the risk of death due to cardiovascular diseases in 5 geographic Brazilian regions. The risk of death significantly increased in the central western region and decreased in the southeastern and southern regions of the country. In the northern region, a trend toward stability was observed, and, for some age brackets, a slight decline was seen. Therefore, an increase in mortality due to cardiovascular diseases in the less developed regions and a reduction in the more developed ones were trends similar to those observed in eastern European countries (less developed countries) and in western countries (more developed), respectively ${ }^{22}$. In the northeastern and central western regions, the risk of death from cardiac ischemic and cerebrovascular diseases increased, cardiac ischemic diseases playing the major role. Mortality due to cardiac ischemic diseases, even though increasing in the central western region, was more pronounced in the southern and southeastern regions. The increase in cerebrovascular diseases was more important in males and females of the central western and northeastern regions; in absolute figures, however, this risk was higher in the southeastern and southern regions. A study carried out in 8 Brazilian capitals also showed a higher incidence of mortality due to cardiovascular diseases in the age bracket from 30 to 69 years in the southern and southeastern Brazilian capitals ${ }^{7}$. The central western region ranked $3^{\text {rd }}$ in the risk of death due to cardiovascular diseases with the same increasing trend of that in the northeastern region. Cerebrovascular diseases were the major cause of death in males and females. The risk of death due to cerebrovascular diseases was close to that of cardiac ischemic diseases in males however it was not true to women who presented a disproportionate greater cerebrovascular death rate. These findings were similar to those of the Brazilian population ${ }^{4}$. The authors showed the 







\begin{tabular}{|lcccccc|}
\hline $\begin{array}{c}\text { Table III - Proportion of deaths due to poorly defined symptoms, } \\
\text { signs, and afflictions* according to the geographical region and sex } \\
\text { in individuals above the age of 30 years. }\end{array}$ \\
\hline Region and sex & 1979 & 1980 & 1987 & 1990 & 1995 \\
\hline Southeastern females & $12 \%$ & $11 \%$ & $9 \%$ & $10 \%$ & $11 \%$ \\
Southeastern males & $13 \%$ & $12 \%$ & $10 \%$ & $11 \%$ & $12 \%$ \\
Southern females & $17 \%$ & $17 \%$ & $15 \%$ & $14 \%$ & $11 \%$ \\
Southern males & $16 \%$ & $17 \%$ & $14 \%$ & $14 \%$ & $11 \%$ \\
Central western females & $19 \%$ & $19 \%$ & $21 \%$ & $14 \%$ & $16 \%$ \\
Central western males & $23 \%$ & $23 \%$ & $24 \%$ & $16 \%$ & $18 \%$ \\
Northern females & $29 \%$ & $30 \%$ & $32 \%$ & $33 \%$ & $32 \%$ \\
Northern males & $32 \%$ & $33 \%$ & $34 \%$ & $34 \%$ & $29 \%$ \\
Northeastern females & $43 \%$ & $48 \%$ & $50 \%$ & $47 \%$ & $41 \%$ \\
Northeastern males & $45 \%$ & $49 \%$ & $51 \%$ & $48 \%$ & $40 \%$ \\
\hline * External causes excluded. & & & & \\
\hline
\end{tabular}

importance of the risk of death due to cerebrovascular diseases, and, therefore, the need for greater investment in detection and treatment of systemic arterial hypertension, the major risk factor for cerebrovascular diseases ${ }^{23-25}$. This is probably the most prevalent risk factor in the Brazilian population and also in patients with coronary artery disease. Therefore, primary and secondary prevention for cardiovascular diseases should initially include the control of arterial hypertension to promote or intensify the declining trend in the risk of death due to cardiovascular diseases. This trend was observed in the southern and southeastern regions, probably resulting from the better identification and control of risk factors, as occurs in more developed countries ${ }^{26-28}$.

The increase in the risk of death in the central western and northeastern regions may have been partially affected by: (1) an improvement in diagnosis of causes of death, and a decrease in poorly defined symptoms, signs, and afflictions from $19 \%$ to $16 \%$ among females and from $23 \%$ to $18 \%$ among males at the end of the period; (2) an increase in urbanization; and (3) a change in the socioeconomic condition in these regions. Improvement in the diagnosis of the cause of death most probably explains, in part, the increasing trend in the risk of death due to cardiovascular diseases in these regions. In the northeastern and central western regions, the proportion of poorly defined deaths was very high, but it showed a gradual decreasing trend between 1979 and 1996. The reduction in the number of poorly defined deaths observed in these regions may have artificially revealed the increasing trend in the risk of death due to cardiovascular diseases. This results from the fact that cardiovascular diseases may account for most poorly defined deaths. Therefore, the reduction observed in poorly defined deaths during the period from 1979 to 1996 results from and explains the increase in the risk of death due to cardiovascular diseases in these regions. Changes in the socioeconomic conditions, even though attractive, may not have played a similar role in the increased trend. On the contrary, the improvement in these conditions is associated with a reduction in the risk of death due to cardiovascular diseases ${ }^{29-31}$.

Data on mortality existing in the information system of the Ministry of Health are subject to limits imposed by the problems that may exist in the origin of these data. Among these problems, we may cite the following: diagnostic errors, deficiencies in filling out death certificates, existence of a proportion of deaths with no clear cause, and typing errors. Studies validating the information on mortality were carried out in the municipality of São Paulo and they showed a good quality of data ${ }^{32,33}$; this type of study, however, does not exist for most states and cities of the country. An indirect indicator of data quality is the proportion of death certificates with poorly defined symptoms, signs, and afflictions as the diagnosis of the cause of death. Good quality data are expected to have a small proportion of this type of diagnosis. In this regard, the northeastern region has the greatest proportion of undefined diagnoses of mortality, which, in 1995, accounted for up to $40 \%$ of the deaths. In $1995,30 \%$ of the deaths in the northern region were poorly defined. In the central western region, $20 \%$ of the deaths were poorly defined, the lowest rates being observed in the southeastern and southern regions, around $11 \%$. No significant difference existed according to sex (tab. III).

In conclusion, the risk of death due to cardiovascular, cerebrovascular, and cardiac ischemic diseases is decreasing in the southern and southeastern regions, which are the most developed regions in the country, and increasing in the less developed regions, mainly in the northeastern and central western regions. The analysis of the trend in the northern, northeastern, and central western regions was impaired by the great proportion of poorly defined causes of death. The increase in the incidence of cerebrovascular and cardiac ischemic diseases in these regions for some age brackets may mean that the risk is higher than that observed simply due to the nonexistence of a diagnosis of the cause of death. The northern region showed a slight decline in the risk of death for some age brackets. The $30 \%$ rate of poorly defined causes of death in this region may mean the existence of a higher risk. However, other studies are required to help understand the trends observed, mainly in the northern, northeastern, and central western regions. Primary and secondary prevention, mainly through identification and control of the major risk factors, such as arterial hypertension and dyslipidemia, should be emphasized in our health services.

\section{Acknowledgments}

We thank SBC/FUNCOR which funded this project entirely and Patrícia Braga and Jaqueline David for their support in data analysis. 


\section{References}

1. American Heart Association. Heart and Stroke Facts, 1998. Dallas: AHA, 1998.

2. The WHO MONICA project. A worldwide monitoring system for cardiovascular disease. World Health Stat Ann 1989; 27: 149.

3. Lotufo PA. Epidemiologia das doenças isquêmicas do coração no Brasil. In: Lessa, I. $\mathrm{O}$ adulto brasileiro e as doenças da modernidade. HUCITEC/ABRASCO, 115-22, SP/RJ, 1998

4. Mansur AP, Favarato D, Souza MFM, et al. Tendência da mortalidade por doenças circulatórias no Brasil de 1979 a 1996. Arq Bras Cardiol 2001; 76: 497-503.

5. Uemura K, Pisa, Z. Recent trends in cardiovascular disease mortality in 27 industrialized countries. Wld Hlth Statist Quart1985; 38: 142-57.

6. Lotufo PA, Lólio CA. Tendência da mortalidade por doença isquêmica do coração no estado de São Paulo: 1970 a 1989. Arq Bras Cardiol 1993; 61: 149-53.

7. Chor D, Fonseca MJM, Andrade CR, Waissmann W, Lotufo PA. Doenças Cardiovasculares: panorama da mortalidade no Brasil. In Minayo MC (ORG.): Os Muitos Brasis. Ed HUCITEC/ABRASCO, SP/RJ, 1995.

8. Laurenti R. The decline of cardiovascular diseases as a cause of death. Rev Saúde Pública 1986; 20: 341-2.

9. Lólio CA, Laurenti R. Tendência da mortalidade por doença cerebrovascular em adultos maiores de 20 anos de idade no Município de São Paulo (Brasil), 19501981. Rev Saúde Pública 1986; 20: 343-6.

10. Walker WJ. Changing U.S. lifestyle and declining vascular mortality -A retrospective. N Engl J Med 1983; 308: 649-51.

11. Kuulasmaa K, Tunstall-Pedoe H, Dobson A, et al. Estimation of contribution of changes in classic risk factors to trends in coronary-event rates across the WHO MONICA Project populations. Lancet 2000; 355: 675-87.

12. Collins R, Peto R, MacMahon S, et al. Blood pressure, stroke, and coronary heart disease. Part 1, Prolonged differences in blood pressure: prospective observational studies corrected for the regression dilution bias. Lancet 1990; 335: 827-38.

13. Eluf-Neto J, Lotufo PA, Lólio CA. Tratamento da hipertensão e declínio da mortalidade por acidentes vasculares cerebrais. Rev Saúde Pública 1990; 24: 332-6.

14. Sytkowski PA, Kannel WB, D'Agostino RB. Changes in risk factors and the decline of mortality from cardiovascular disease. NEngl J Med 1990; 322: 1635-41.

15. Ministério da Saúde. Fundação Nacional da Saúde. DATASUS. Sistema de informação sobre mortalidade 1979-1997: dados de declaração de óbito. [CD-ROM] Brasília, 1998.

16. Cláudio DM, Marins JM. Cálculo numérico computacional. São Paulo: Atlas, 1989.

17. Fundação IBGE. Censo demográfico Goiás: VIII Recenseamento Geral-1970. Rio de Janeiro, 1973. (Série Regional, I)

18. Fundação IBGE. Censo demográfico: dados gerais-migração-instrução-fecundidade-mortalidade. Rio de Janeiro, 1982. (Recenseamento geral do Brasil 1980, 9: v.1, t.4).
19. Fundação IBGE. Censo demográfico 1991: resultados do universo relativo às características da população e dos domicílios. Rio de Janeiro, 1994. n.27: Goiás

20. Fundação IBGE. Contagem da população 1996. Rio de Janeiro, 1997. v.1. (Resultados relativos a sexo da população e situação da unidade domiciliar).

21. Neter J, Kutner MH, Nachtschiem CJ, Wasserman W. Applied Linear Statistica Models. $4^{\text {th }}$ ed. Chicago: Irwin Series in Statistics, 1996: p.217-489, 567-614.

22. Stegmayr B, Vinogradova T, Malyutina S, Peltonen M, Nikitin Y, Asplund K Widening gap of stroke between East and West. Eight-year trends in occurrence and risk factors in Russia and Sweden. Stroke 2000; 31: 2-8.

23. Mcgovern PG, Burke GL, Sprafka JM, Xue S, Folsom AR, Blackburn H. Trends in mortality, morbidity, and risk factor levels for stroke from 1960 through 1990. The Minnesota Heart Survey. JAMA 1992; 268: 753-9.

24. Modan B, Wagener DK. Some epidemiological aspects of stroke: mortality/morbidity trends, age, sex, race, socioeconomic status. Stroke 1992; 23: 1230-6.

25. Derby CA, Lapane KL, Feldman HA, Carleton RA. Trends in validated cases of fatal and nonfatal stroke, stroke classification, and risk factors in southeastern New England, 1980 to 1991: data from the Pawtucket Heart Health Program. Stroke 2000; 31: 875-81

26. Haskell WL, Alderman EL, Fair JM, et al. Effects of intensive multiple risk factor reduction on coronary atherosclerosis and clinical cardiac events in men and women with coronary artery disease. The Stanford Coronary Risk Intervention Project (SCRIP). Circulation 1994; 89: 975-90.

27. Gillum RF. Trends in acute myocardial infarction and coronary heart disease death in the United States. J Am Coll Cardiol 1994; 23: 1273-7.

28. McGovern PG, Pankow JS, Shahar E, et al. Recent trends in acute coronary heart disease-mortality, morbidity, medical care, and risk factors. The Minnesota Heart Survey Investigators. N Engl J Med 1996; 334: 884-90.

29. Iribarren C, Luepker RV, McGovern PG, Arnett DK, Blackburn H. Twelve-yea trends in cardiovascular disease risk factors in the Minnesota Heart Survey. Are socioeconomic differences widening? Arch Intern Med 1997; 157: 873-81.

30. Osler M, Gerdes LU, Davidsen M, et al. Socioeconomic status and trends in risk factors for cardiovascular diseases in the Danish MONICA population, 19821992. J Epidemiol Community Health 2000; 54: 108-13

31. Hoeymans N, Smit HA, Verkleij H, Kromhout D. Cardiovascular risk factors in relation to educational level in 36000 men and women in The Netherlands. Eur Heart J 1996; 17: 518-25.

32. Laurenti R. Características da mortalidade por doença isquêmica do coração em adultos de 15 a 74 anos no município de São Paulo. Arq Bras Cardio 1981; 36: 95-9.

33. Laurenti R. Mortalidade de mulheres em idade fértil no município de São Paulo (Brasil) 1986 - metodologia e resultados gerais. Rev Saúde Pública 1990; 24 128-33. 